\title{
MIGUEL SOLER EN LA TIERRA DE LOS VALIENTES. LA MINA, URUGUAY, 1954-1961
}

\author{
Miguel Soler in the land of the brave. La Mina, Uruguay, 1954-1961
}

\section{María García Alonso*}

\author{
Dice mi padre que ya llegará \\ desde el fondo del tiempo otro tiempo \\ y me dice que el sol brillará sobre un pueblo \\ que él sueña labrando su verde solar. \\ Alfredo Zitarrosa, Adagio en mi país (1978)
}

Resumen. En 1954 tuvo lugar en el Uruguay rural una de las experiencias educativas más innovadoras de la década: el Primer Núcleo Escolar Experimental de La Mina. Fue dirigida por Miguel Soler Roca, un maestro hispanouruguayo que había sido becado para estudiar educación fundamental en el CREFAL poco tiempo después de la creación de este organismo. En 1958 Margaret J. Anstee, representante de la ONU en Uruguay, se desplazó a La Mina para hacer un reportaje que permitiera mostrar las claves del éxito de la propuesta y explorar la posibilidad de utilizar la experiencia como modelo inspirador en otras latitudes. El presente texto transcribe dicha entrevista, inédita hasta el momento, contextualizándola con otros documentos que explican el devenir de esta iniciativa.

Palabras clave: Núcleo Escolar; Educación Fundamental; Educación rural en Uruguay.

Abstract. In 1954, one of the most innovative educational experiences of the decade took place in rural Uruguay: the First Experimental School Nucleus of La Mina. It was directed by Miguel Soler Roca, a Spanish-Uruguayan teacher who had been awarded a scholarship to study basic education in CREFAL, shortly after the creation of this organism. In 1958 Margaret J. Anstee, Representative of the UN in Uruguay, went to La Mina to interview him. She thought that it would show the keys to the success of the proposal and would explore the possibility of exporting the experience as an inspiring model in other latitudes. The present text transcribes this interview, unpublished until

\footnotetext{
* Departamento de Antropología Social y Cultural. Facultad de Filosofía. UNED. Despacho 112. Edificio de Humanidades. C/ Senda del Rey 7. 28040 Madrid. España.mgarciaal@fsof.uned.es
} 
now, contextualizing it with other documents that explain the development of this initiative.

Keywords: School Nucleus; Fundamental Education; Rural education in Uruguay.

Desde el año 2009 he tenido con Miguel Soler numerosas conversaciones. Hace tiempo que he dejado de llamarlas entrevistas. Por eso, al plantearme plasmar por escrito alguna de ellas, me sorprendió el pudor de traicionar con ello la calidez, la hondura y el afecto de las palabras dichas, la intimidad de los espacios domésticos, los tiempos de la vida privada que su mujer Matilde y él me han permitido compartir con una generosidad difícil de encontrar en un hogar que no sea uruguayo. Además, Miguel tiene ahora 95 años. Sigue escribiendo con lucidez y la sutileza de sus reflexiones continúa intacta, pero no conviene cansarle con esfuerzos innecesarios. A su edad se ha ganado el derecho a no ser molestado con preguntas trascendentes.

Así que decidí, con su permiso, centrarme en una entrevista que le hizo Margarita J. Anstee - representante de la ONU en Uruguay-, en torno a 1958, cuando era Director del Primer Núcleo Experimental de La Mina, para que sirviera de publicidad a su propuesta en un momento en el que se pensaba que podría ser un buen modelo para replicar en otros lugares de América Latina. Esta grabación se preservó milagrosamente del despojo al que sometieron La Mina cuando la experiencia fue desamparada, primero, y hundida después, por unas autoridades educativas que ya se estaban preparando para el Golpe de Estado que acabaría con décadas de excelencia en la educación pública uruguaya. Sobrevivió también al exilio de Soler y le acompañó de país en país durante años. Estaba en su casa de Montevideo en un viejo casete, en la estantería del pasillo donde la música de tantas partes del mundo donde trabajó y vivió se junta con retazos de su propia vida. La tecnología le dio una nueva existencia que nos permite ahora escuchar y transmitir la fuerza de ese proyecto con las voces de los que lo llevaron a cabo.

La transcripción comentada de la entrevista se acompaña de un enlace que permite su audición. ${ }^{1}$ Escucharemos a Miguel Soler, con su acento

\footnotetext{
${ }^{1}$ El enlace a la grabación se encuentra en http://espacio.uned.es/fez/ficheros/manes_varios/GRABACION_NUCLEO_DE_LA_MINA.wma. Se sugiere su audición a la vez que se lee la transcripción.
} 
mestizo catalán y uruguayo, hablar sereno y orgulloso de la validez de su experimento de educación fundamental; a Anstee con sus constantes manifestaciones de interés ante lo que estaba grabando. También la voz de niña de la enfermera Clementina Pérez, lo que nos permite imaginarnos con mayor claridad a esta joven cabalgando sola por las llanuras infinitas de Cerro Largo rumbo a los rancheríos apartados. O a don Rivero con su deje campesino. O los alumnos cantando acompañados del acordeón de Nelly Couñago, primera esposa de Soler, en una tarde de primavera cuando los naranjos todavía estaban en flor. La audición merece la pena, sin duda.

Este documento sonoro está contextualizado por otros textos del propio Soler que explican: por un lado, la importancia del trabajo que desarrollaron un conjunto de personas -y las instituciones que las apoyaron- para transformar las condiciones de vida de un pedazo olvidado de la «campaña» uruguaya; por otro, las enormes trabas burocráticas y políticas que por distintos motivos se pusieron para que se llevara a cabo esta tarea. A excepción de la carta que Miguel Soler escribió en 1961 al Director de Enseñanza Primaria y Normal² todos los textos que aquí se presentan son inéditos.

El primero de ellos es un fragmento de un correo electrónico de 24 de septiembre de 2017 en el que Soler cuenta cuáles fueron las circunstancias en las que se desarrolló la grabación. He aquí su explicación.

Miss Margaret Joan Anstee era inglesa, joven y bella. En aquellos tiempos —el Núcleo había empezado a fines del 54estábamos todos embarcados en la promoción del desarrollo comunitario y, como se explica en la grabación, la educación fundamental era el aporte educativo a ese desarrollo, el ingrediente que en el sector educativo integraba políticas, programas y proyectos basados en el cambio con fuertes dosis de participación popular consciente y organizada. Eran los años fuertes de la CEPAL, ${ }^{3}$ de D. Raúl Prebisch y del desarrollismo planificado. Margaret, que hablaba un perfecto español y ya había cumplido misiones en Filipinas y Colombia, buscaba en Uruguay iniciativas que res-

\footnotetext{
${ }^{2}$ Se ha utilizado un mecanuscrito proporcionado por su autor.

${ }^{3}$ La Comisión Económica para América Latina y el Caribe es un organismo dependiente de la ONU que trata de promover el desarrollo económico y social de las regiones más desfavorecidas de Latinoamérica. Raúl Prebisch fue su Secretario General entre 1950 y 1963.
} 
pondieran a ese enfoque del desarrollo y en algún momento fue a parar a La Mina. Nos hizo una primera visita, quedó encantada y quedamos todos amigos.

De ahí en adelante, hizo todo lo posible por ayudar en términos siempre concretos a nuestro trabajo: nos prestó un generador que nos permitía exhibir cine; nos encontró múltiples becas para nuestro personal; nos dejaba el dinero de sus viáticos como donación; nos mandó especialistas de agencias de Naciones Unidas; comentó el trabajo en la prensa; intercedía ante las autoridades de la enseñanza procurando resolver problemas; consiguió que el Director General Adjunto de la UNESCO, Malcolm Adisheshia, viajara en un avión militar hasta La Mina, manteniendo una visita memorable con los jóvenes de nuestra zona... En fin, hacía cuanto podía, que dentro de nuestra pobreza incidía notablemente.

Su empresa más importante fue lograr que se incluyera a La Mina en el programa de cupones de la UNESCO que recaudaba fondos en el mundo desarrollado en favor de proyectos del mundo pobre. Comenzaron a llegarnos unos cupones en dólares cuya finalidad era la compra de un vehículo $4 \times 4$ para el Núcleo. Cuando la suma alcanzó, yo inicié la compra ante un importador de Montevideo. Toda importación, naturalmente, estaba sometida a impuestos y el valor de lo que teníamos que pagar eran varios miles de dólares, tantos como el valor de la compra. No teníamos cupones para tanto. Yo, por un lado, y los inspectores que apoyaban la experiencia y sobre todo Margaret por otro, empezamos a tramitar la exoneración de aquel impuesto, con el argumento de que se trataba de una importación para un servicio del Estado. No hubo caso. Los Ministerios de Relaciones Exteriores y de Economía se negaron a suprimir el impuesto. Yo tuve que devolver los cupones, Margaret tuvo que explicar a la UNESCO la absurda actitud de una parte de nuestro Gobierno y yo quedé habilitado para decir, como sigo diciendo, que el nivel de comprensión de los organismos internacionales de lo que estábamos haciendo en La Mina superaba al nivel de comprensión del gobierno uruguayo. Agrego que, tiempo después, cuando ya Margaret no trabajaba en Uruguay, se creó una Asociación de Amigos del Núcleo de La Mina que se aplicó a reunir donaciones en pesos uruguayos 
que nos permitieron comprar un camioncito Ford de los años treinta, tan viejecito que vivía más en los talleres mecánicos que en nuestros caminos. Pero eso es otra linda historia, con lindas personas detrás, como ocurre siempre.

Margaret fue trasladada a Bolivia. Más tarde a Chile y allí, donde yo también trabajaba, vivimos el Golpe de Estado de Pinochet e hicimos de todo para auxiliar extranjeros perseguidos. Después nos encontramos en distintos lugares y oportunidades, casi siempre en reuniones de NN.UU. Ya jubilados, mantuvimos correspondencia. Pasó a vivir a Inglaterra. Celebró sus 90 años de edad en junio de 2016 y falleció el 25 de agosto de ese mismo año.

Vuelvo a la grabación. En una de sus visitas Margaret llevó una grabadora y recogió material para procesarlo después. Más tarde nos llevó una casete (de las antiguas, de cinta) con el reportaje, único que existe sobre el Núcleo de entonces.

\section{ENTREVISTA REALIZADA EN EL PRIMER NÚCLEO ESCOLAR EXPERIMENTAL DE LA MINA, CERRO LARGO (URUGUAY) POR MARGARET J. ANSTEE, REPRESENTANTE DE LAS NACIONES UNIDAS EN DICHO PAÍS (EN TORNO AL AÑO 1958)}

[Los niños de la escuela comienzan a cantar la canción Vidalita a Cerro Largo. Esta canción fue popularizada por la folklorista Amalia de la Vega a finales de los años 50 y asumida en el Núcleo como parte de un programa no escrito de dignificación de la identidad uruguaya a través de la música, muy necesaria para fortalecer la cohesión de grupos sociales que no tenían un arraigo territorial muy definido. Su letra tiene directa relación con el modo de empezar la entrevista de Ansteee y dice así:

Soy de Cerro Largo, vidalita, entre el gran follaje.

Cerro Largo mío, vidalita, que yo quiero tanto.

Brilla esplendoroso el trigal dorado

Donde corazones, vidalita, triunfan de la muerte.

Soy de Cerro Largo, vidalita, tierra del gauchaje

Con sonrisa y canto, vidalita, del ceibal y el río.

Tierra de valientes, vidalita, y de naranjales.

Cerro Largo mío, vidalita, que yo quiero tanto.] 
MARGARET J. ANSTEE: Sí. Estamos en Cerro Largo, Departamento de la República Oriental de Uruguay, donde linda con el Brasil. Tierra del gauchaje. Tierra del valor y del naranjo en flor. Es un Departamento que se destaca por su riqueza ganadera, sus campos de pastoreo y el paisaje hermoso y apacible, cuyas cuchillas blancas y extendidas le dan su nombre. La ciudad de Melo, capital de este Departamento, a unos $400 \mathrm{~km}$ de Montevideo, capital del país, es laboriosa y próspera. Pero nosotros hemos venido más lejos aún, una hora y pico de viaje, a un poblado rural, cuyo nombre, La Mina, fue poco conocido hasta algunos años atrás, pero que ahora comienza a hacer historia. Hice mención en conferencias internacionales sobre temas educacionales en Panamá, Venezuela, Washington, París... porque aquí, desde el año 1954 se está desarrollando un ensayo de educación fundamental, primera experiencia de esta índole que se ha llevado a cabo en el Uruguay. Se llama el Primer Núcleo Escolar Experimental de La Mina.

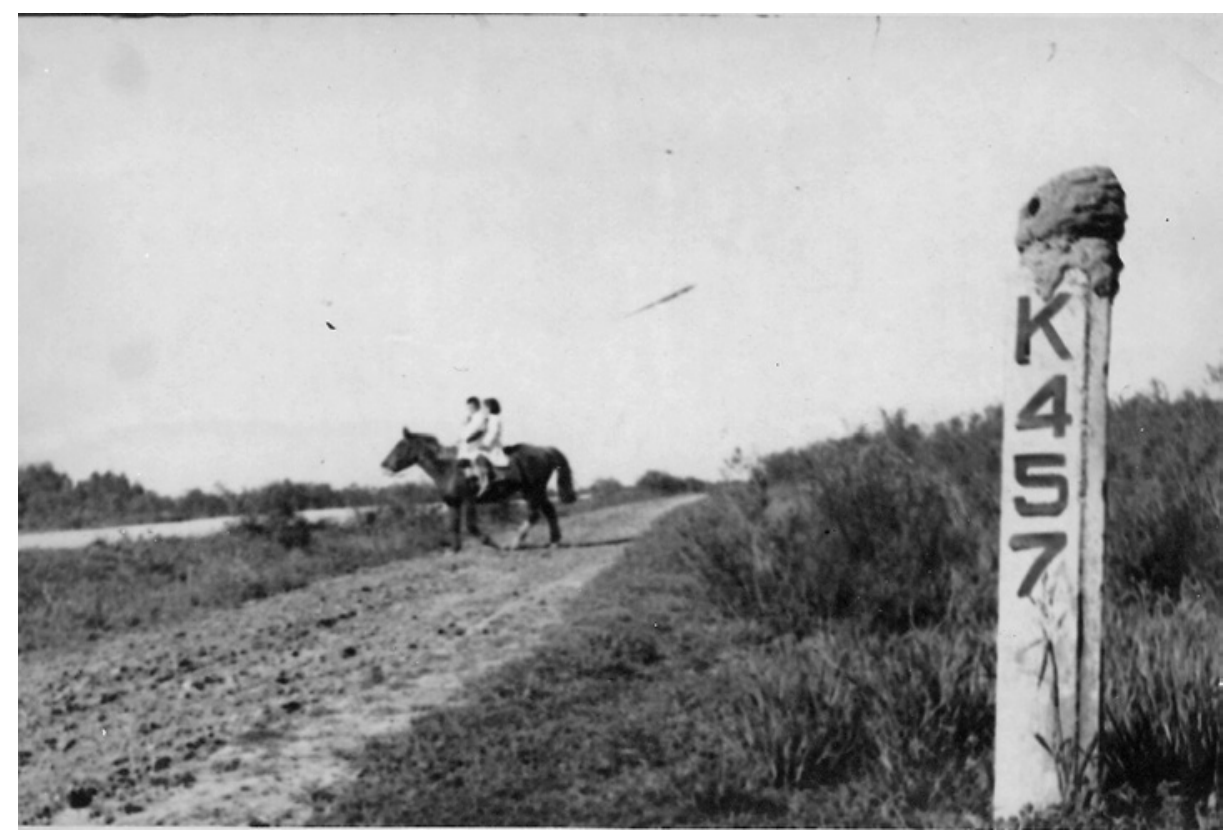

Cruce de caminos que conducía a la Escuela Central del Núcleo de La Mina (Archivo de Miguel Soler, años cincuenta) 
Retrocedamos en el tiempo. En el año 1952, un grupo de educadores uruguayos fue becado por la UNESCO para asistir a un curso de dieciocho meses en el CREFAL: el Centro Regional de Educación Fundamental en América Latina, en Pátzcuaro (México). Allí estudiaron los principios de la educación fundamental y su aplicación práctica al ambiente latinoamericano. A su regreso al Uruguay, uno de ellos, el maestro Miguel Soler, empieza a trabajar en La Mina. Pero como tenemos al lado al mismo señor Soler, le vamos a dejar a él que explique el cómo surgió esta idea y por qué eligió La Mina para su realización.

MIGUEL SOLER: Durante varios años, trabajé en escuelas rurales de diferentes zonas del país. Al regreso del Centro de Pátzcuaro pensé que el Consejo Nacional de Enseñanza Primaria y Normal podía realizar una obra de progreso poniendo en marcha un ensayo de educación fundamental en algunas de las regiones del norte del país, donde la existencia de muchos problemas económicos, sociales y culturales, garantizaba un buen aprovechamiento de ese tipo de educación.

MARGARET J. ANSTEE: Y ¿por qué fue llamado Primer Núcleo Escolar Experimental el proyecto?

MIGUEL SOLER: Bueno, en algunos países americanos se han fortalecido las escuelas rurales, organizándolas en núcleos escolares. Esto quiere decir que varias escuelas trabajan en estrecha colaboración, asistidas por un equipo de especialistas que actúa en toda su área. En nuestro núcleo funcionan siete escuelas. Ésta en la que estamos es la Escuela Central, la de La Mina. Las otras seis son escuelas seccionales. El Núcleo Escolar de La Mina, por ser el primero del país, ha tenido un carácter experimental al poner en práctica los métodos preconizados por la UNESCO en una región uruguaya de pequeños agricultores.

MARGARET J. ANSTEE: Tal vez usted nos podría decir ¿qué profesionales componen el equipo de especialistas?

MIGUEL SOLER: Sí, con mucho gusto. Disponemos de una enfermera, una maestra de hogar, una experta en manualidades femeninas, un ingeniero agrónomo, un experto agrario, un maestro para la producción de materiales audiovisuales y una maestra de educación estética. 
MARGARET J. ANSTEE: Y ella es su señora ¿no es cierto? [Se refiere a Nelly Couñago que también se encontraba presente]

MIGUEL SOLER: Ciertamente. Ella también estuvo en Pátzcuaro y hace años que trabaja en educación rural.

Quería agregar, señorita Anstee, que el ingeniero agrónomo ha sido designado por el Ministerio de Ganadería y Agricultura, y la enfermera por el de Salud Pública. En esta forma coordinada, nuestro proyecto cubre los tres aspectos fundamentales del bienestar rural, o sea, la producción, la salud y la educación.

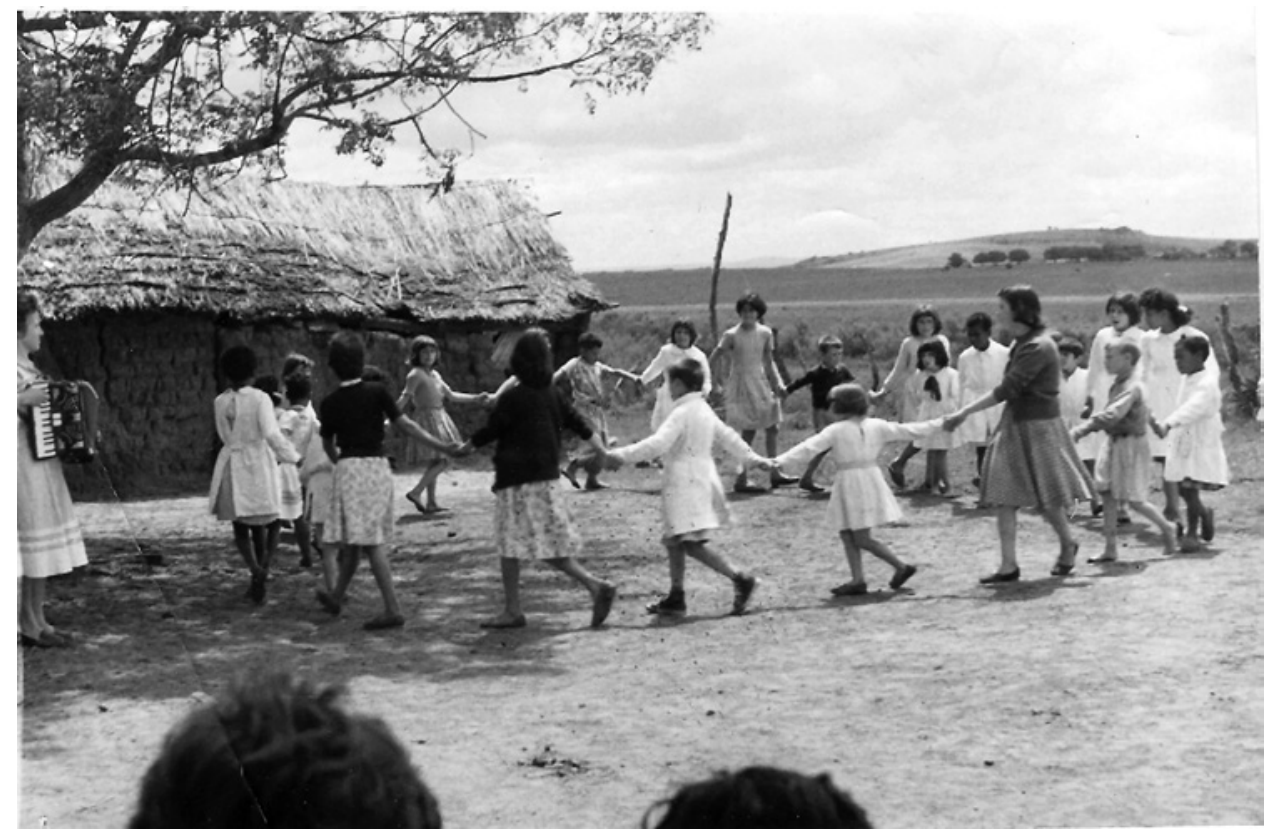

Nelly Couñago (a la izquierda) toca el acordeón para que bailen los niños. Escuela-rancho del Núcleo de La Mina (Archivo de Miguel Soler, años cincuenta)

MARGARET J. ANSTEE: Yo entiendo que la finalidad del Núcleo es atender tanto las necesidades de la escuela como las de la comunidad en general, ¿cómo se cumple ese propósito?

MIGUEL SOLER: Con la ayuda del cuerpo de especialistas, los diecisiete maestros que atienden las escuelas, y desde luego sin renunciar a su misión específica de educar a la infancia, dedican algunas horas del 
día al desarrollo de proyectos de trabajo con adultos, como por ejemplo reuniones de capacitación de mujeres, el deporte y la recreación juvenil, la colaboración con la enfermera, campañas a favor de las huertas familiares, el blanqueo de las viviendas, la construcción de muebles sencillos, la administración del servicio médico vecinal.

MARGARET J. ANSTEE: A propósito de esto, me han dicho que mañana, domingo, funcionará la clínica encargada de este servicio. De manera que tal vez podríamos hablar con el médico y los vecinos afiliados.

MIGUEL SOLER: Sí. Creo que será muy interesante para usted; porque, realmente, este servicio nos ha dado muchas satisfacciones.

MARGARET J. ANSTEE: Sí, pero creo que tenemos que agregar que éste es solamente uno de los distintos éxitos del Núcleo. Y creo que inicialmente, el proyecto de La Mina dispuso de un periodo experimental de tres años ¿verdad? Recuerdo que a su término yo tuve el gusto de asistir a las reuniones de evaluación, donde los maestros, los especialistas y los supervisores discutieron su trabajo; llegando, si recuerdo bien, a conclusiones muy favorables respecto a la organización y métodos que se habían ensayado acá. Dígame ¿qué perspectivas de futuro abre esta evaluación?

MIGUEL SOLER: Bien, en base al informe de nuestros supervisores y a la petición escrita de los siete vecindarios, el Consejo de Enseñanza Primaria dispuso la continuación de nuestro trabajo por tres años más. Además de esto, está el estudio del mismo Consejo de un proyecto de creación de todo un sistema de núcleos escolares, de manera que el método se iría extendiendo a otras zonas del país de características similares. Con vistas a esta intención, algunos de nuestros maestros han sido becados al extranjero por organismos internacionales. Los que hemos quedado aquí no descuidamos nuestra capacitación, celebrando cada quince días reuniones de acuerdo y de estudio. Justamente, el personal está ya listo para iniciar la sesión de hoy sábado, de modo que usted nos hará el honor de acompañarnos, señorita.

MARGARET J. ANSTEE: Con muchísimo gusto. 
Nos incorporamos a la reunión, en la cual se han abordado temas tan importantes como la filosofía de la educación fundamental y la sociología rural. Este día la reunión se dedica al estudio de temas específicos relacionados con el trabajo en la zona. En estos momentos, la maestra del hogar ha finalizado una charla sobre alimentación, la cual origina, como es costumbre, un intercambio general de ideas:

NELLY NAVARRETE, MAESTRA DE HOGAR: La gente, teniendo por ejemplo el boniato, no hace variedad de comidas con el boniato; por ejemplo, budín de boniato. La gente come el boniato en la sopa o en el puchero y nada más. No lo utiliza de distintas maneras y debía hacerlo: una mejora en los platos, una mejor presentación.

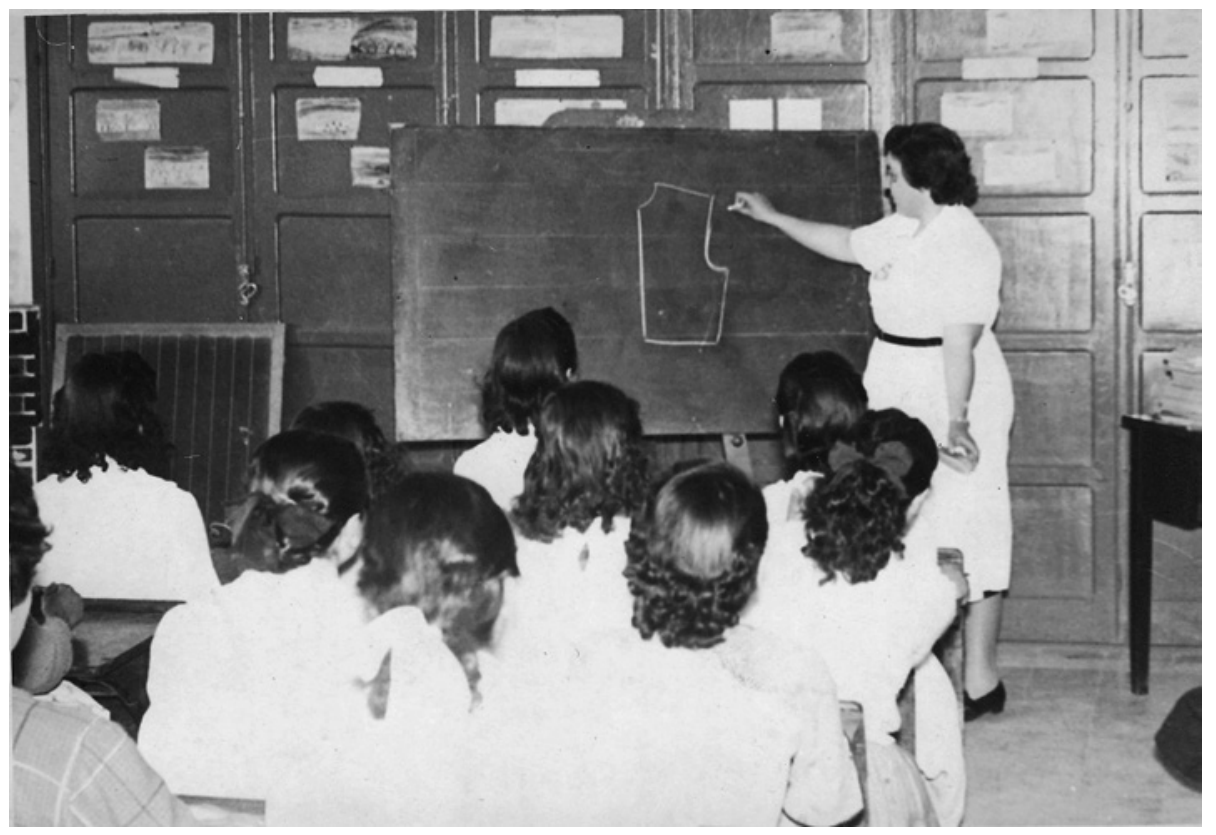

Nelly Navarrete, maestra de hogar dando clase de corte y confección (Archivo de Miguel Soler, años cincuenta)

INTERVIENE OTRA MAESTRA: Es un problema de divulgación de las distintas comidas que se pueden hacer. Esto lo podemos hacer perfectamente bien teniendo recetas de comida y dándole esas recetas a la dueña de casa. Y en las reuniones de mujeres y eso hacer demostraciones prácticas frente a ellas para que vean cómo preparar el alimento de otra forma. 
MARGARET J. ANSTEE: Le ha correspondido después al ingeniero agrónomo informar sobre esos conceptos de su especialidad, y en estos momentos finaliza su exposición diciendo:

SR. BESSÓN, INGENIERO AGRÓNOMO: Voy a hacer una breve descripción de las formas de sembrar en los distintos trabajos culturales: las épocas de siembra, las cosechas... En fin, todo lo relacionado con las distintas especies.

MARGARET J. ANSTEE: Una de las características del trabajo del Núcleo Escolar Experimental es alternar el trabajo, que es muy intenso, con los cantos y danzas típicas de la región. Así, esta reunión termina con el baile nacional: El Pericón, dirigido por la maestra de educación estética.

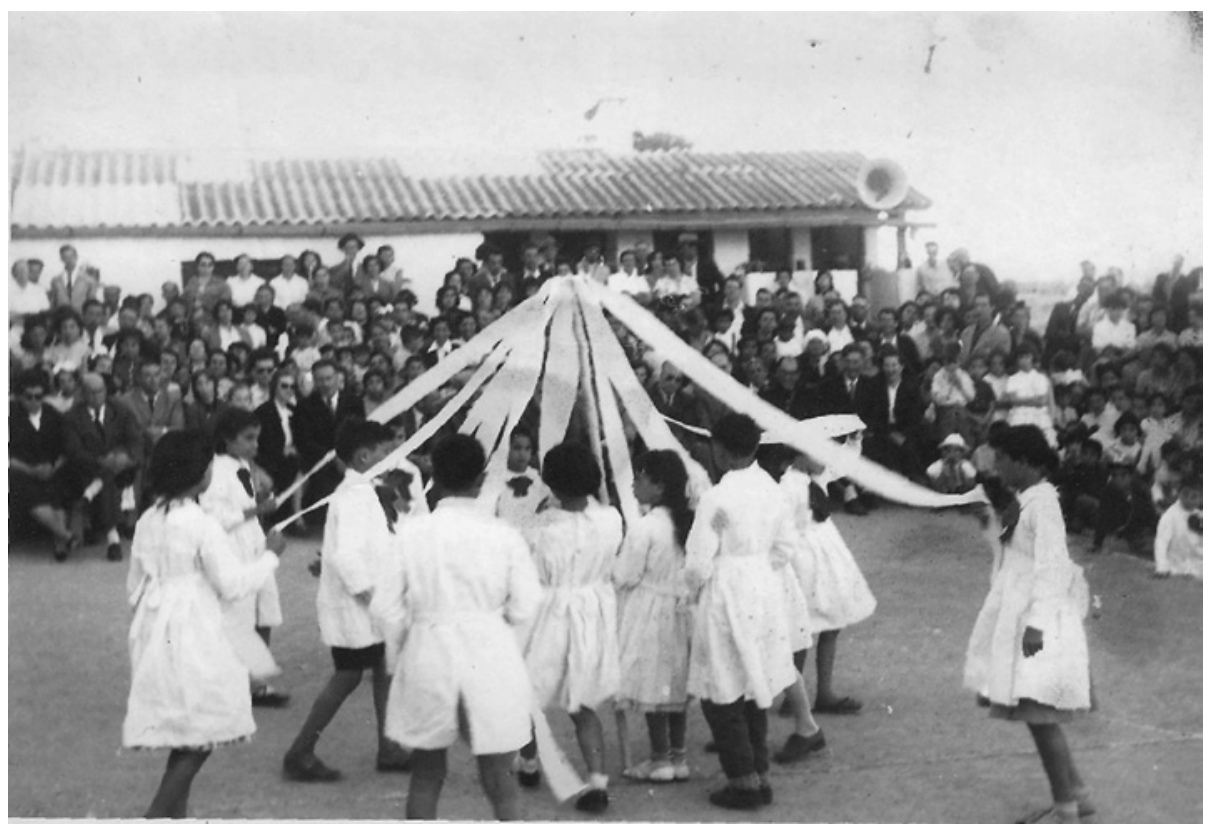

Niños bailando el «Pericón» en una fiesta de la Escuela Central del Núcleo de La Mina (Archivo de Miguel Soler. Años cincuenta)

[Nelly Couñago da instrucciones sobre cómo organizar el baile mientras toca el acordeón. «La primera figura delantera. Compañeros, a los dos flancos para los muchachos y la derecha para jóvenes. Estad atentos. No empiecen por ninguna figura [...] Y no pueden cambiar tampoco sin oír la voz de aura (ahora). ¿Están listos?» Comienza la música del baile de una grabación. Una voz masculina da instrucciones sobre los movimientos] 
[La entrevista se reanuda el día siguiente]

MARGARET J. ANSTEE: Es domingo, y un nuevo día de actividad. Comienza a funcionar el servicio médico vecinal, y al respecto me parece interesante destacar que, justamente hace un año, me tocó presenciar la reunión de los vecinos en la cual pidieron los primeros pasos para la ordenación de este servicio, que funciona con el sistema de compartida. En esa oportunidad fue elegido presidente de la Comisión directiva un vecino del lugar, a quien pediremos que nos hable del servicio médico vecinal. Don Rivero, por favor.

DON RIVERO: Este tema se desarrolló en una reunión aquí que formaba el Núcleo, con sus entusiastas con empeño de llevar esta zona hacia adelante, porque se trataba de una zona realmente atrasada, y que no había ningún desarrollo ni ninguna especie. Entonces entre las tantas reuniones surgió esta idea aquí entre nosotros los vecinos, e inclusive ellos también, con esa gran voluntad que tienen de mejorar la situación en esta zona y se llevó hacia adelante. Precisamente se encontraba en esa reunión, en esa oportunidad, la señorita que representa a las Naciones Unidas, que por suerte fue el día que culminó el éxito de que pudiéramos llevar hacia adelante, y que concretamos realmente el asunto del servicio médico. Actualmente marcha en pleno desarrollo. Hemos tenido la gratitud de ver tantas cosas que si se quieren se pueden, cosas que en un principio no creíamos que pudieran pasar. Pero hemos llegado al final de cumplir nuestros deseos, de que tenemos todo en plena marcha y estamos totalmente satisfechos.

MARGARET J. ANSTEE: Ahora vamos a pasar la palabra a la señorita Alba, que es maestra de escuela y que también es tesorera de la comisión, y ella nos va a decir cómo los vecinos van pagando sus cuotas para el servicio médico.

SRTA. ALBA, MAESTRA Y TESORERA DE LA COMISION DE SANIDAD: Bueno, la administración del servicio médico está a cargo de una comisión. Esa comisión está formada por algunos vecinos, por la enfermera y por una maestra de la escuela, que hace las veces de tesorera. Tengo el honor de haber sido nombrada por los compañeros de esta escuela para actuar en esta comisión. En general, les puedo decir que el servicio cuenta ahora con noventa familias afiliadas. Cada familia afiliada paga 
una modesta suma de 1,50 por mes, y tienen derecho a la asistencia médica todos los integrantes de cada una de esas familias.

MARGARET J. ANSTEE: Precisamente en este momento, acaba de salir el Doctor Matos, ya que ha terminado de trabajar con todos los clientes de hoy, los últimos se acaban de ir en los caballos para sus casas. El Doctor Matos viene dos domingos por mes, de la ciudad de Melo, que queda a una distancia de $70 \mathrm{~km}$. Y fue hasta allá que anteriormente la gente tenía que ir cuando necesitaba servicio médico. Doctor, ¿a cuánta gente atiende usted cada vez que viene aquí?

DOCTOR MATOS: Sí. El promedio mensual actualmente se ha elevado. Está alrededor de cuarenta o cuarenta y cinco personas mensuales; haciendo dos o a veces tres visitas al servicio médico de aquí. ¿Alguna otra pregunta?

MARGARET J. ANSTEE: Sí. Yo quisiera preguntarle ¿cuáles son en realidad los problemas de salud más destacados que usted ha notado en esta zona?

DOCTOR MATOS: Problemas médicos sobresalientes dentro del área del Núcleo no hay ninguno. El problema que yo creo que es fundamental es la alimentación, sobre todo en los niños pequeños, de edad preescolar alguno, pero esto no es un problema muy sobresaliente, no es muy intenso y actualmente ya está en vías de recesión.

MARGARET J. ANSTEE: Y esto ya se vincula con otro trabajo del Núcleo, que es tratar de mejorar la alimentación por vía de la educación, del cuidado del hogar. Ahora, yo entiendo que lo más normal del trabajo que hacen ustedes aquí en la clínica es asistencial ¿verdad? Tal vez ahora podríamos preguntar a la señorita enfermera, que también se encuentra aquí, qué puede hacer ella, qué está haciendo actualmente como medicina preventiva y en qué consiste su trabajo diario en el Núcleo.

CLEMENTINA PÉREZ, ENFERMERA: Bueno, mi trabajo aquí es esencialmente preventivo, pero a esto se suma mucho lo asistencial. ¿En qué consiste mi trabajo? Bueno, yo asisto a las familias de las siete zonas del Núcleo, y ahí puedo ver todos los problemas, especialmente de madres embarazadas y de niños preescolares. Eso y la enseñanza sanitaria. La enseñanza a los niños es sobre alimentación, sobre higiene y todos los 
problemas que tengan; igual a las madres, el control médico periódico y traerlas a la clínica preventivas.

MARGARET J. ANSTEE: Y cuénteme, ¿cómo viaja usted? Yo entiendo que usted tiene que cubrir un área bastante grande.

CLEMENTINA PÉREZ: Sí, es grande. Son siete zonas. ¿Cómo viajo? Bueno, a caballo la mayor parte de las veces, a veces en tractor, y a algunas casas más cercanas a pie y a veces, cuando se dispone de un auto, que es muy raro, también.

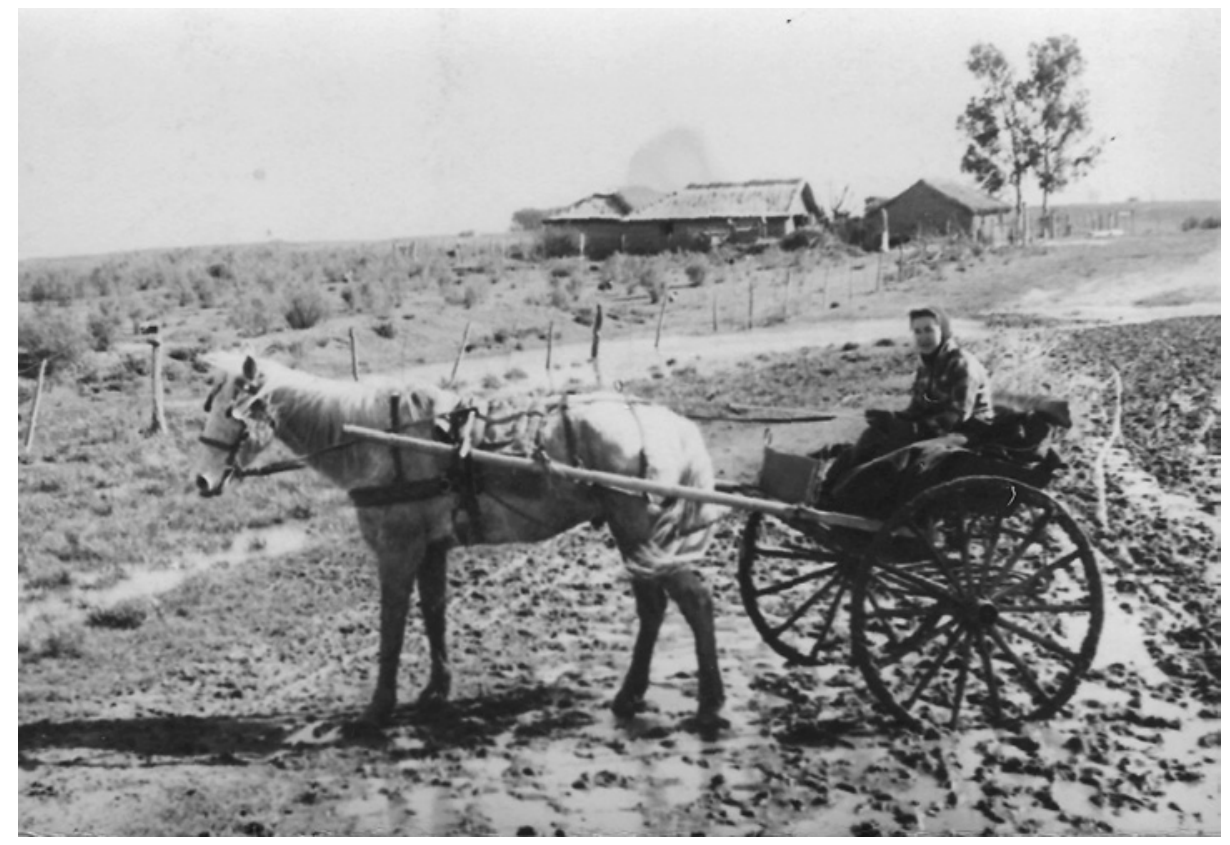

Clementina Pérez, enfermera del Núcleo, yendo de visita domiciliaria (Archivo de Miguel Soler, años cincuenta)

MARGARET J. ANSTEE: Así que usted tiene una vida llena de peripecias. Entiendo que usted tiene muchas veces también que salir de noche ¿No tiene usted alguna anécdota que podría contarnos de algo que le ha pasado en el camino alguna vez?

CLEMENTINA PÉREZ: Sí, un susto bien grande, que veníamos de Melo con el doctor y el caballo se nos desbocó y corría y corría y no lo podíamos detener. Y cuando llegamos estaba sin frenos. 
MARGARET J. ANSTEE: ¡Qué horror! Pero por fin llegaron bien, que es lo principal. Muchas gracias.

Pues pensábamos que ya todos los que iban a venir al servicio médico esta mañana ya habían venido, pero parece que el tiempo ha detenido a algunos. Porque ahora precisamente vemos llegar un charret ${ }^{4}$ con tres personas, uno de ellos un niño. Todos vienen tapaditos contra la lluvia con ponchos porque es una mañana muy fea. Ahora están bajando del charret y vamos a preguntar a la señora para qué viene.

Buenos días señora, ¿cómo está usted?

PACIENTE: Bien.

MARGARET J. ANSTEE: Usted me podría decir ¿para qué viene esta mañana a la clínica?

PACIENTE: Para consultar al nenito, que está enfermo.

MARGARET J. ANSTEE: Y ¿es la primera vez que viene a la clínica?

PACIENTE: No, desde el principio he venido.

MARGARET J. ANSTEE: Y parecería que ustedes vienen de muy lejos, ¿podría decirme de dónde?

PACIENTE: ¿Cuántos kms? $5 \mathrm{~km}$.

MARGARET J. ANSTEE: Y cada vez que viene ¿viene en el charret?

PACIENTE: A veces vengo a caballo.

MARGARET J. ANSTEE: ¿Y cuando viene a caballo trae el niño con usted?

PACIENTE: Sí, traigo al niño.

MARGARET J. ANSTEE: Y ¿adónde van después? ¿Van directamente a la casa?

PACIENTE: Sí, directa a la casa vamos.

MARGARET J. ANSTEE: Y, dígame, ¿usted ha encontrado algún mejoramiento en el niño desde que viene acá?

\footnotetext{
${ }^{4}$ Se trata de un pequeño carro tirado por un caballo.
} 
PACIENTE: Sí, ¿cómo no? No sabía sentarse, no sabía caminar, no se para. Ahora da pataditas.

MARGARET J. ANSTEE: Ah, esa debe ser una gran alegría para usted.

PACIENTE: Sí, ¿cómo no?

MARGARET J. ANSTEE: Y efectivamente, la alegría es una de las características del grupo de maestros, técnicos, alumnos y vecinos de este ensayo, que cuenta con el interés de la UNESCO, públicamente expresado; y que constituye un valioso aporte al proyecto principal que desarrolla dicho organismo para el mejoramiento de la enseñanza primaria en toda América latina. Y al retirarnos de tan amable lugar, nos acompañan las mismas voces de los niños que nos recibieron, cantando esta vez, el himno del Núcleo: La Escuelita Rural, cuyos sencillos primeros versos dicen
Entre trigales dorados, entre un monte y un maizal, rodeada de luz y trinos está mi escuela rural. El murmullo del trabajo con las risas y el cantar...

[Y continúa la canción escrita por Soler — que se ha convertido con el tiempo en el himno escolar por excelencia de la escuela rural uruguaya-, con las voces de los niños y el acordeón de Nelly Couñago:
... Todo el día sube al cielo
que la escuela es colmenar.
Vamos, amigos,
a trabajar;
hombres y niños
sin descansar.
La tierra que es generosa
pan dorado puede dar.
El niño que es esperanza
puede ayudar a sembrar.
Las semillas que en la tierra
nuestras manos sembrarán
sombra, leña, flor y fruto, 
otro día nos darán.

Vamos, amigos,

a trabajar;

hombres y niños

sin descansar.

Hay un rincón en mi Patria

que es para todos igual:

su bandera azul y blanca

en mi escuelita rural.]

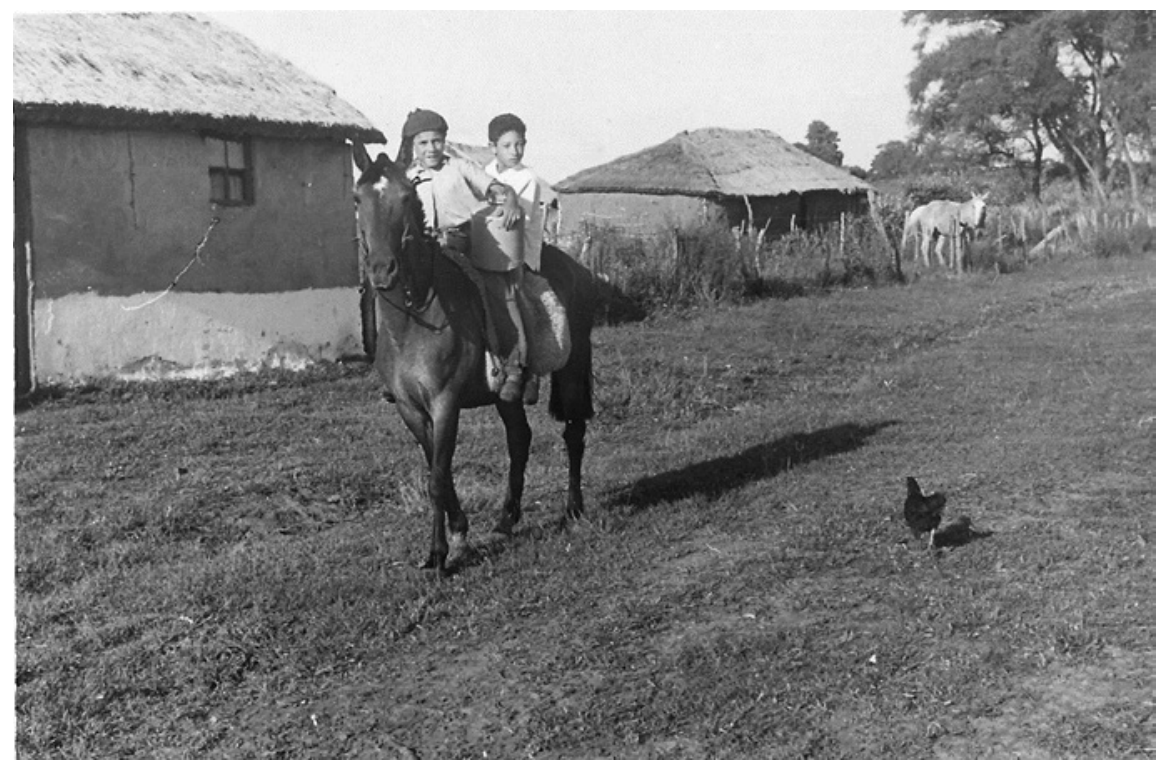

Niños yendo a la escuela (Archivo de Miguel Soler, años cincuenta)

Este reportaje se hizo en el Primer Núcleo Escolar Experimental de La Mina, departamento de Cerro Largo. Los trabajos de montaje fueron realizados por el Departamento de Grabación de CX16 Radio Carve Montevideo, República Oriental del Uruguay.

\section{EL FIN DE LA MINA}

El siguiente documento, y el más amargo, es la carta que presentó Miguel Soler ante el Consejo de Enseñanza Primaria el 20 de marzo de 1961. En ella presentaba su renuncia al cargo de Director del Primer 
Núcleo Escolar Experimental de La Mina. Esta carta ha sido reproducida por él mismo en varias ocasiones prácticamente desde el momento mismo de su escritura. ${ }^{5}$ Entre ellas en su libro Réplica de un maestro agredido (2005), en el que respondía casi treinta años después a la sarta de infamias que aparecieron en el libro Testimonio de una nación agredida (1978), publicado por el Comando General del Ejército para justificar la represión. En el prólogo de este último se afirma que «un grupo de Jefes del Ejército han realizado este volumen sobre la base de una amplísima documentación incautada por los organismos de seguridad a movimientos subversivos, así como el testimonio de sus principales dirigentes». ${ }^{6}$ Como no podía ser de otra forma, estos Jefes dedican unos párrafos al trabajo de Miguel en Cerro Largo:

Miguel Soler presenta su proyecto «Primer Centro Experimental de La Mina», aprobado por la Federación Uruguaya de Magisterio, e ingenuamente por el Consejo Nacional de Educación Primaria en 1957.

El Núcleo Experimental de la Mina, en su estructura, funcionamiento, filosofía y objetivos, se dirige a nuclear la acción educativa de los centros rurales sobre la base del dominio de las poblaciones marginadas. Un objetivo que luego aparece especialmente destacado dentro de los planes de «guerrilla rural» de los Tupamaros.

En 1957 comenzó a operar el Núcleo de la Mina, bajo la dirección del ya nombrado Soler, secundado por Henry Ruiz, Irma Piedracueva de Ruiz, Susana Iglesias, Juan José Araújo, Nelly Navarrete de Lucas, Teresita Cazarre, Miriam Brayer, Sonia Brayer, Lucho Fuentes, Miriam Luchas, Arturo Fernández, etc. [...].

El grupo fue desarmado en 1960 por el Dr. Felipe Ferreiro. Miguel Soler abandona el país, se refugia en la UNESCO, donde actúa como secretario privado del Director General, ${ }^{7}$ lo que no le

\footnotetext{
${ }^{5}$ La primera vez fue publicada por la Comisión Especial para la Defensa de la Educación Rural de la FUM, Montevideo 1961.

${ }^{6}$ Comando General del Ejército, Testimonio de una nación agredida (Montevideo: División de Publicaciones y Ediciones Universidad de la República, 1978), 5.

${ }^{7}$ Como podrá comprobarse en la breve cronología de las actividades de Miguel Soler que aparece al final del texto, nunca estuvo entre ellas ser secretario del Director General de la UNESCO. En 1974 se convierte en Director de la División de Alfabetización, Educación de Adultos y Desarrollo Rural
} 
impide aún autodesignarse en 1975 como representante del Uruguay en el Simposio Internacional de Alfabetización de Irán el 3 de septiembre de $1978 .^{8}$

Leamos ahora la renuncia y la defensa del maestro Soler, escrita premonitoriamente antes de ser formalmente acusado de subversivo.

La Mina, 20 de marzo de 1961

Sr. Director General de Enseñanza Primaria y Normal,

Dr. Felipe Ferreiro.

Sr. Director General:

He tomado conocimiento de la resolución que el día 13 de marzo último dictó el Consejo Nacional de Enseñanza Primaria y Normal en relación con el funcionamiento del Primer Núcleo Escolar Experimental de La Mina, Cerro Largo, que hasta el momento he tenido el honor de orientar y dirigir.

Ante dicha resolución me considero en el deber de elevar a Vd. mi renuncia al cargo de Director del Núcleo que con carácter interino se me asigna en la misma.

Entiendo que las razones de este acto deben quedar claramente documentadas, porque así lo requieren la importancia pedagógica del asunto y mi conciencia de maestro.

El Núcleo Escolar ha funcionado durante seis años, finalizando ahora su segundo ciclo experimental de tres años. A la hora de dar opinión sobre la labor cumplida y de pronunciarse sobre el futuro de la institución, el Consejo comienza por declarar «que no existen suficientes elementos de juicio que habiliten a criterio del Consejo para juzgar respecto al resultado de la obra escolar y social, cumplida hasta el presente por el Núcleo Escolar Experimental de La Mina, y que ello se debe en gran parte, al régimen que implantara la resolución del 7 de octubre de 1954, ya que por el sistema de contralor que establece, se dio intervención exclusiva al Cuerpo de

de esta organización, y por ello tuvo un destacado papel en el Congreso de Irán que tanto irritó a los militares.

${ }^{8}$ Comando General del Ejército, Testimonio de una nación agredida, 221. 
Inspectores Regionales, desentendiéndose el Consejo del ejercicio de potestades que sólo a él pertenecen legítimamente».

Todo el resto de los considerandos, así como el contenido preciso de la resolución, están dedicados a impugnar y modificar aspectos de la resolución del 7 de octubre de 1954, por la que el propio Consejo de Enseñanza puso en marcha el Núcleo Escolar.

No hay en el documento una palabra de contenido técnico, ni una referencia al trabajo cumplido con niños, jóvenes y adultos, ni una resonancia a las inquietudes que La Mina ha despertado en el magisterio y en la opinión pública, ni una mención a la documentación existente en carpetas de ese Consejo, ni siquiera un asomo de gratitud a más de veinte jóvenes educadores que durante seis años sirvieron con devoción un ideal tan respetable como el de la escuela rural.

La experiencia sobre la cual el Consejo que Vd. preside debió haber opinado, es ignorada en el documento y esta ignorancia es la que confiere a la resolución una invalidez técnica definitiva.

El Consejo señala no estar en condiciones de opinar y atribuye la culpa a un régimen que, según dice, otorgaba todas las competencias a las Inspecciones Regionales sin reservar ninguna al propio Consejo. Me atrevo a señalar la falsedad de este argumento: sin duda las Inspecciones Regionales, cualesquiera sean las atribuciones que se les confieran, están sometidas a la superior jerarquía administrativa del Consejo. A casi dos años de haber iniciado su actuación, la Mayoría del Consejo no puede, recién, advertir y sostener que una institución bien definida del organismo escapaba a su contralor. Y digo «la Mayoría» porque me consta que los Sres. Consejeros de la Minoría están en condiciones de discutir acerca del Núcleo de La Mina en planos más elevados, atendiendo más a fines y a realizaciones que a aspectos reglamentarios.

Pero ya que el propio Consejo manifiesta no poseer suficientes elementos de juicio en esta materia, yo me he de permitir reforzar su propia tesis, recordando que existen otras razones, mucho más poderosas que la que da el Consejo, para explicar su desconocimiento. 
Apenas instalado el actual Consejo de Enseñanza, los miembros de la Comisión Asesora de Educación Rural, entre los cuales me contaba, solicitamos ser recibidos por el Consejo. Deseábamos cambiar ideas respecto a los servicios de la Sección Educación Rural, uno de los cuales es precisamente el Núcleo de La Mina. Solicitó la audiencia verbalmente el Sr. Inspector Técnico, Presidente de la mencionada Comisión Asesora, y meses más tarde, debió hacerlo por escrito. La audiencia no fue concedida y nunca se cursó recibo de un largo informe que se nos requirió, como sustituto del fértil cambio de ideas alrededor de una mesa de trabajo.

Tampoco provocó el comentario oficial la cartilla «A propósito de la Educación Rural en el Uruguay», elaborada por la Sección Educación Rural, ni mereció un simple acuse de recibo la cartilla "Cinco años de Educación Rural en La Mina». Ambas fueron enviadas a los cinco señores Consejeros y daban cuenta de los temas que hoy declara desconocer el Consejo.

En octubre de 1959 visitó el Núcleo de La Mina el Sr. Ministro de Instrucción Pública y Previsión Social, Dr. Eduardo Pons Echeverry. No fue invitado por el Consejo Nacional de Enseñanza, sino por un funcionario internacional, la Srta. Margaret J. Anstee, Representante de la Junta de Asistencia Técnica de Naciones Unidas en nuestro país, quien seguía con la mayor atención nuestra experiencia. Me consta que el Sr. Ministro hizo lo posible por llegar a La Mina en compañía de alguno de los señores Consejeros. No lo consiguió, perdiendo así el Consejo una oportunidad de tomar conocimiento directo de los trabajos que se cumplían en la zona.

En diciembre de 1960, diez y ocho integrantes del personal del Núcleo Escolar viajamos a Montevideo para entrevistarnos con todos los Sres. Consejeros, hacerles saber que el segundo plazo experimental de tres años había finalizado y exponerles algunos puntos de vista relativos al futuro de los núcleos escolares, elaborados días antes en jornadas cumplidas en La Mina con la presencia y ayuda de los Sres. Inspectores Regionales y del Sr. Inspector Departamental. Como sería innecesario aclarar, debimos costearnos los gastos de estadía y los que provocó un viaje 
de casi mil kilómetros. El Sr. Director General nos escuchó atentamente durante media hora sin comprometer opinión sobre los asuntos que le presentó la delegación. El Consejero Maestro Sr. Mascaró nos hizo saber por su Secretaria que no nos recibiría, pues a su juicio bastaba con que hubiéramos conversado con el Sr. Director General. El Consejero Maestro Sr. Cazarré escuchó nuestro anuncio respecto a la finalización del plazo concedido a la experiencia, pero se negó rotundamente a oír idea alguna relativa al futuro de la institución, que era, desde luego, el motivo determinante del viaje y de las entrevistas. Los Consejeros de la Minoría, Sres. Gómez Haedo y Vidal dedicaron a la delegación por lo menos una hora cada uno, escucharon sus planteamientos, aportaron sus propias ideas y comprometieron pleno apoyo a la etapa de ampliación del sistema de los Núcleos Escolares, que en aquel momento creíamos segura, ya que los presupuestos presentados al Parlamento tanto por la Mayoría como por la Minoría, incluían los cargos necesarios para hacer funcionar cuatro Núcleos Escolares.

¿Habrá necesidad de decir que el resultado de nuestro viaje no nos satisfizo y que, sin poderlo evitar, la forma en que fuimos atendidos por la Mayoría nos causó dolor y nos llenó de temores?

Agréguense a todo esto las dificultades existentes para tener entrevistas con el Sr. Director General en la propia sede del Consejo, donde no existe un régimen de concesión de audiencias que garantice el tratamiento oportuno de los problemas que afectan al servicio o a los funcionarios, de lo que tengo ingrata y reciente experiencia personal.

Ahora el Consejo de Enseñanza, por voto de su Mayoría, declara no estar en condiciones de juzgar. No puede admitirse que se señalen, como causa de esa situación, los presuntos defectos de la resolución que puso en funcionamiento el Núcleo. La falta de «suficientes elementos de juicio» que invoca el Consejo proviene de esta actitud general de desconocimiento y del hecho de no haber sometido a análisis ciertos documentos existentes en el organismo, tales como los informes de visitas del Inspector Departamental, el dictamen de fines de 1957 de los señores Inspectores Regionales y Departamental, las notas enviadas por los ve- 
cinos en la misma fecha, los compromisos contraídos con la UNESCO, la recomendación de la Comisión de Presupuesto de estabilizar el Núcleo de La Mina y crear otros, el testimonio del Sr. Ministro de Instrucción Pública emitido en el Paraninfo de la Universidad, y otros muchos.

El texto de la resolución del Consejo de Enseñanza de 13 de marzo no merece, finalmente, ser analizado en detalle, por cuanto su carencia de fundamentación válida le quita seriedad, reduciéndolo a la condición de un documento lesivo para los realizadores de la obra.

La primera razón, pues, de mi renuncia radica en la falta de un pronunciamiento concreto del Consejo de Enseñanza sobre el trabajo que durante seis años se ha cumplido en La Mina.

Veamos ahora un segundo aspecto de la cuestión cuya exposición no puedo evitar.

El Consejo de Enseñanza no ha conocido directamente el trabajo de La Mina. Pero quienes se aproximaron a él, desde muy distintos lugares del país y del mundo, sintieron invariablemente cuánta emoción había en la tarea. Nuestro trabajo no debe medirse por sus obras materiales, ni tampoco porque haya ensayado nuevos recursos pedagógicos. Miramos con modestia la obra realizada. Aún nos parece muy alejada de la que debe llegar a ser. Pero tenemos la pequeña vanidad de haber entrado a fondo en el corazón de los niños, los hombres y las mujeres. Estamos seguros de haberles ganado, no sólo en afecto hacia nosotros, sino en actitud hacia sí mismos y hacia la colectividad. El esfuerzo que por su voluntad realizaron los jóvenes educadores de La Mina, entre los que debemos tener una palabra de especial recordación para las Enfermeras Universitarias, ha dado frutos. No les importó la lluvia, el barro, el frío y el calor, el sacrificio del descanso bien ganado y el renunciamiento a mejores posiciones. Su esfuerzo resultó siempre bien compensado. Se vivió en la zona un proceso de desarrollo espiritual, sanitario, económico, cultural y familiar, pacientemente estimulado por el ejemplo de todos los días y de todas las noches de este grupo de maestros. No hacían, 
desde luego, nada extraordinario, ni iban más allá que cualquiera de sus colegas conscientes del deber. Pero tenían a su favor la gran ventaja de trabajar unidos fraternalmente y siempre con una canción en los labios.

Yo he sido casual promotor y atento testigo del despertar profesional de estos jóvenes maestros, algunos de los cuales ingresaron al Núcleo como estudiantes magisteriales, pero supieron exponer años más tarde su experiencia en otras tierras de América.

Y esta devota y emocionante contracción al trabajo del equipo de La Mina, ganaba a quienes nos visitaban, ganaba a nuestros supervisores, ganaba a nuestros vecinos. Algunas veces, solemnes discursos oficiales hicieron alusión a este hecho, tan sencillo pero en cierta medida inusitado, de que los jóvenes maestros de La Mina sacrificaran otras posiciones y comodidades para estar allí, sirviendo con tanta dificultad y con tan escasos medios su ideal de ayudar desde la escuela a vivir mejor a los hombres. Y nadie crea que todo el mérito viene del sacrificio y de la emoción. Ellos son también maestros profesionalmente maduros y valiosos.

Ahora el Consejo ha dispuesto otra cosa. Ya no podremos hablar del equipo de La Mina. De veintidós maestros, cinco, en el mejor de los casos ocho, quedan en La Mina; los demás se alejan obligadamente, dejando su lugar a nuevos colegas. ¡Qué felices nos hubiéramos sentido si este alejamiento hubiera obedecido a la puesta en marcha de los cuatro Núcleos Escolares que el Consejo de Enseñanza incluyó en su inicial proyecto de presupuesto!

Yo no puedo aceptar esta medida y ver sin protesta cómo la mayoría de mis compañeros de trabajo dejan a su pesar La Mina. Estaba en las manos de la autoridad subordinar los reglamentos a las necesidades del servicio y no lo inverso, como ha sido hecho. Y esto no sólo por razones de orden humano, muy de tener en cuenta en este caso, sino también por una razón de orden técnico que aconseja que quienes han adquirido especialización útil al país sean aprovechados en los cargos correspondientes a esa especialización, como es el caso concreto de diez compañeros que tienen seis años de actuación en La Mina. Siete de ellos han salido al exterior a recibir entrenamiento 
ajustado a nuestro plan de trabajo. Todos han sido calificados con altas notas, todos han de estar ausentes, de ahora en adelante, de la zona donde quieren seguir actuando y donde aún se les necesita.

Digo entonces que mi renuncia obedece en segundo término a la imposibilidad personal de aceptar estas disposiciones del Consejo, no porque resista trabajar con otros colegas, sino porque de algún modo, y yo no tengo otro a mi alcance que la renuncia, debo rechazar este trato que se da al equipo de La Mina.

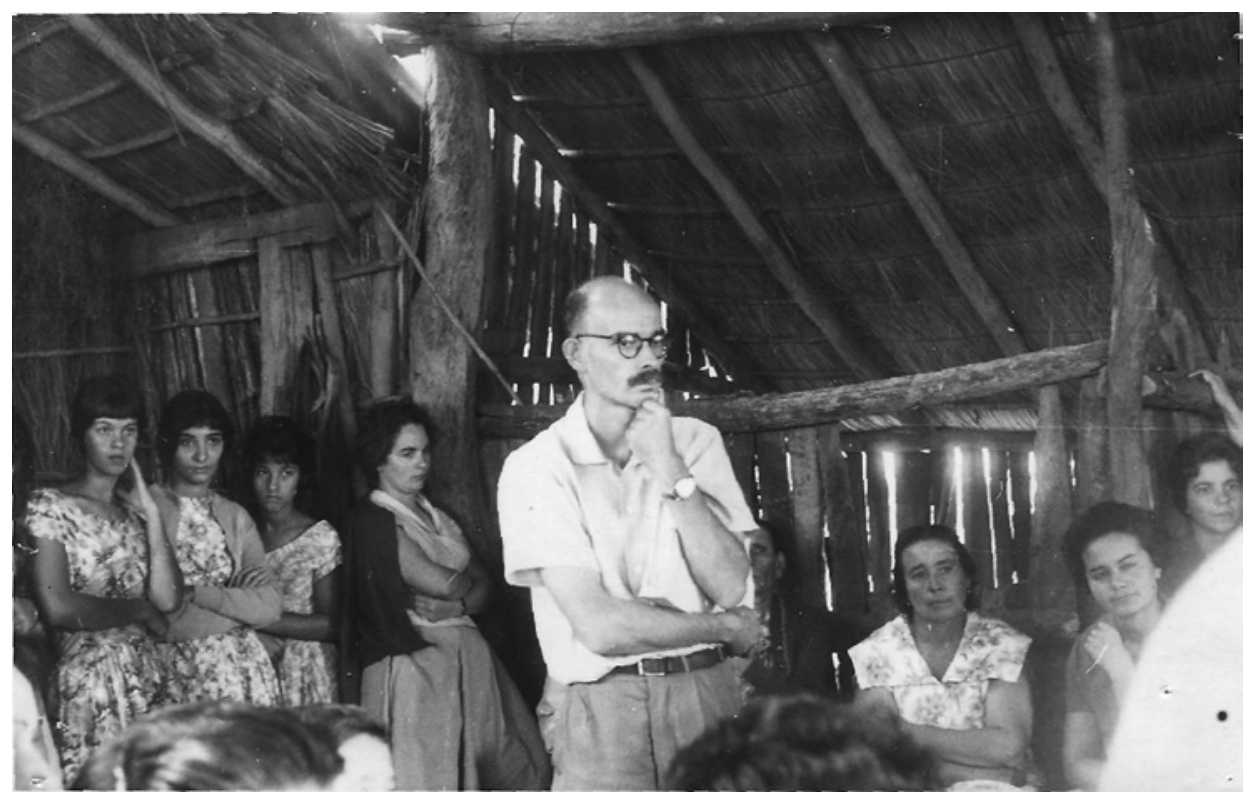

Miguel Soler en una reunión vecinal (Archivo de Miguel Soler, años cincuenta)

Tratemos finalmente de ver, porque es indispensable, lo que debió ser motivo de claro pronunciamiento técnico, cualquiera fuera el signo del dictamen.

¿Qué es lo que está en juego en este momento en La Mina?

Hay quienes tienden a tratar los problemas del hombre en base a abstracciones. Privado de una sustentación real, su pensamiento se vuelve evasivo, impreciso, frío. 
En materia de educación, esta tendencia conduce a las generalizaciones, a los enunciados vacuos, a las apelaciones al Hombre eterno, que es un hombre distinto a cada uno de los hombres que conocemos. La pedagogía que resulta de ello es presuntuosa e inútil. Quiere ser cierta para tantos seres que acaba por no venirle bien a ninguno. La educación deviene una simple especulación académica, más que un instrumento al servicio de la vida.

La experiencia de muchos años me ha enseñado que la educación no puede dar la espalda a la vida. Ella es parte de la vida misma, de la vida como acontecer concreto en la jornada de los individuos y de las colectividades. Esta no es una concepción materialista. Creo que la aventura humana es más digna cuanto más libre y más alto sea el vuelo del espíritu. Pero, siguiendo a Vaz Ferreira, no puedo dejar de tener en cuenta los fundamentos reales de los idealismos.

Cuando por primera vez actué frente a niños descalzos, sucios, hambrientos, hace ya de esto bastantes años, comprendí que ser educador era realmente un compromiso simultáneo con la realidad cargada de problemas y el ideal poblado de esperanzas. No podía en mi angustiado trabajo de maestro joven sustraerme a ninguno de los términos de esta ecuación. El presente y el futuro se contradecían brutalmente y no era nada fácil, en aquella mi soledad inicial del rancherío norteño, escapar al clamor de una realidad dolorosa, seducido por la imagen de un mañana mejor.

Después, por todos los caminos de nuestra América encontré el mismo cuadro. Mayorías famélicas y discursos en torno a la grandeza del destino común. El C.R.E.F.A.L. me hizo comprender la responsabilidad de la educación en esta tarea de aproximar las miserias del hombre presente a su grandeza de futuro. Y me indicó caminos. El círculo vicioso de la ignorancia, la miseria y la desesperación que mantiene ahogados a millones de hombres, puede ser vencido por la educación. Es posible, lo será siempre, hacer resurgir en el hombre el ansia de la vida plena. Despierto o adormecido, el impulso que nos lleva a todos hacia adelante es la fuerza más poderosa de la humanidad. Una parte de ella puede concretarla en mayor bienestar, en progreso creador, en elevación 
material y espiritual. Pero para más de mil millones, por razones distintas y complejas, la idea de que es posible una vida sin hambre y sin desesperación, no pasa de ser una intuición, un anhelo o un hecho totalmente ignorado.

Las últimas décadas han sido testigo de hechos sociales que tienen el sentido de una reparación y de un despertar. Tras la segunda guerra mundial, pueblos enteros han logrado su independencia y ha sido sometida a la discusión común la cuestión del desarrollo de aquellas zonas donde el hombre, más que gozar la vida, la padece. Así han surgido instituciones, proyectos, métodos de trabajo que, al recoger la vieja experiencia del hombre en su lucha por la dignidad, la sistematizan y le dan el carácter de una gigantesca empresa común. La educación, dentro de este cuadro, ha comenzado a tener el sentido de una acción recuperadora, de una marcha atrás para alentar a los rezagados y acortar la distancia que los separa de los niveles de vida ya alcanzados por otros.

La educación fundamental, la educación de la comunidad, la educación de adultos, la educación rural, traducen un propósito común de servir al hombre en los términos más realistas, haciendo de la toma de conciencia de sus problemas actuales el comienzo de una lenta pero persistente obra de desarrollo. Todos aquellos que han asumido la responsabilidad de este enfoque educativo y han sabido conectarlo debidamente con los esfuerzos en los campos económico, político y social, han llegado a la conclusión de que la educación es herramienta indispensable en esta gran tarea de borrar de nuestro globo la vergonzosa mancha de la miseria.

América tiene también analfabetismo y hambre, pueblos que desean ansiosamente liberarse de la angustia, y esfuerzos educativos que extienden por llanuras y montañas la buena nueva de que ello es posible. Todo esto tiene el sentido de lo necesario, de lo que surge de las raíces mismas del Continente, para llevar inexorablemente al florecimiento de sociedades felices. Me parece que es simplemente una cuestión de tiempo, más que de principios. Éstos son claros: el sentido dinámico moderno de la democracia no puede ser otro para los americanos que el de un 
gran esfuerzo colectivo por hacer efectiva la libertad, basándose en la satisfacción plena de todas las necesidades humanas. Un hombre desesperado no es un hombre libre, aunque las leyes hablen de él como si lo fuera.

Al Uruguay le ha hecho un daño tremendo su especial ubicación en el conjunto americano. Durante muchos años nos ha resultado favorable toda confrontación. Hoy, no sólo se ha agudizado la pobreza general de los campesinos, sino que ha entrado en ellos, progresivamente, el descreimiento en las posibilidades de la vida rural y el ansia de retomar la ruta de progreso emigrando a las ciudades, en tanto en éstas se mira con azoramiento creciente un porvenir amenazado por la subproducción del país. No existe en nuestra patria ningún esfuerzo organizado por enfrentar la realidad. Artigas continúa esperando quien prosiga su obra de transformación agraria. Nuestras producciones rurales básicas están estancadas pese al formidable avance universal de la técnica. Durante todo este siglo hemos hablado de la inhumana coexistencia del latifundio y del rancherío, limitándonos a verlos crecer, el uno en su opulencia, el otro en su frustración humana. Se ha ido acentuando en gobernantes y pueblo una actitud de indiferencia hacia los problemas sociales del campo. Son problemas aparentemente menores, porque gran parte de los habitantes del país trabajan, comen, tienen techo y gozan de la vida. Entre tanto, decenas de miles carecen de trabajo permanente, comen ensopados aguados, habitan en ranchos insalubres y aprenden desde el nacimiento que la vida no es pródiga en risas y canciones.

Yo he oído decir al Sr. Director General que el habitante de nuestros campos disfruta prácticamente de un mismo nivel de vida que el de las ciudades. Ello puede ser relativamente cierto para algunas regiones del país, pero los maestros de muchas zonas campesinas hemos visto a niños de vientre hinchado por la malnutrición, afiebrados sobre cojinillos, separados del médico por muchas leguas de mal camino. Hemos visto a las madres envejecidas prematuramente, con el rostro endurecido por la ansiedad, privadas de sociabilidad y esperanza. Hemos visto a muchos jóvenes valiosos huir del trabajo escaso y mal pagado para refugiar su hambre de seguridad en los cuarteles. Hemos visto a hombres 
maduros, perdida ya la ilusión de la lucha creadora, levantando como parias ranchos cada vez más pobres, para terminar en la triste condición de pensionistas o de habitantes de un suburbio a donde nunca hubieran ido a parar con los suyos si la buena tierra les hubiera ofrecido pan y esperanza. Sí, conocemos bien este cuadro, que señala una existencia rural muy distinta de la urbana, que denuncia un trauma social y que constituye un desafío a nuestras fuerzas de educadores. Durante años gritamos, luego discutimos, hoy sencillamente trabajamos. Y todo el que ha querido tener ojos y oídos sabe que la escuela rural se ha afirmado, año tras año, en esta convicción: o se inicia donde haga falta una acción educativa recuperadora, o nuestras gentes humildes del campo seguirán deslizándose hacia una definitiva frustración.

Este es asunto de clara competencia del Consejo Nacional de Enseñanza Primaria y Normal, porque, sin perjuicio de reconocer en qué gran medida es también un problema que atañe a todos los órganos del gobierno y a todos los ciudadanos de la República, sin duda la educación debe cumplir en tales casos su función primaria y transmitir al hombre las conquistas del hombre, entre las que están tanto aquellas que se refieren a la vida material como las que tocan a la espiritualidad. Los maestros del campo reclamamos un puesto de trabajo en el esfuerzo nacional por liberar del miedo y la incertidumbre a buena parte de la población rural y no daremos un paso atrás en nuestra ya vieja resolución de hacer de nuestras escuelas centros de vida y esperanza. Y aunque a algunos de mis colegas les resulte molesta la exigencia, o a los observadores del afán ajeno pueda parecerles mistificación o quimera, repito que cabe a la escuela rural y a sus maestros la responsabilidad de promover en niños, jóvenes y adultos el legítimo deseo de una vida de plenitud. Si así no fuera, si esta necesaria función no fuera comprendida por los profesionales obligados a cumplirla o por las autoridades llamadas a apoyarla, la educación carecería de sentido y traicionaría el destino de nuestros hijos.

Es claro que esta actitud progresista provoca cambios y que los cambios traen nuevos problemas. Pero, ¿puede alguien desear el estancamiento de la nación? Las consecuencias sociales y políticas de este planteamiento no deben asustarnos. No puedo entender 
que la política sea algo desligado de la vida y por tanto, no la concibo sino sirviendo al progreso del hombre, en lo que creo que tiene muchos puntos de contacto con la educación. Y así, me parecería del más alto interés nacional que políticos y educadores estuviéramos de acuerdo en asignar a la escuela del campo una función fundamental en la transformación de la vida social, encomendando a los maestros que junto a los médicos y a los agrónomos, hoy casi ausentes del escenario campesino, promovieran, por todos los medios a su alcance, la incorporación de hombres y mujeres al patriótico propósito de mejorar su nivel de vida, hoy deficitario. Hay dos maneras de encarar estos angustiosos problemas de nuestro campo: la agitación demagógica y el trabajo técnico constructivo. Me parece indispensable que hagamos todos los mayores esfuerzos a favor de esta segunda fórmula.

A esta concepción de la política educacional que el país necesita nos referimos los maestros cuando hablamos de «educación rural», palabras que hoy son impugnadas por el Sr. Director General, pero que para nosotros resultan apropiadas, porque resumen tanto como nuestro pensamiento, nuestra actitud y nuestra esperanza.

No estoy seguro de que siempre deba ser así, pues no he pretendido enunciar verdades inmutables que por otra parte no existen en materia de educación, sino señalar una clara responsabilidad de presente.

Sería excesivo por extenso, aunque no innecesario, detallar todo lo que los maestros hemos hecho por llegar a este punto y destacar el inmenso cariño con que hemos ido dando nacimiento y desarrollo a cada una de las instituciones necesarias al cumplimiento de estos fines. Estaría fuera de lugar también explicar ahora que el Núcleo de La Mina es parte de este proceso y entrar a dar cuenta aquí de sus fines, de sus métodos y de sus logros. El trabajo está aquí, en La Mina, abierto a quien quiera saber de él y el Consejo de Enseñanza Primaria cuenta, si desea emplearlas, con vías de asesoramiento correcto. Pero una conclusión dolorosa surge con total claridad y ella es que la supresión de la Sección Educación Rural y de los Núcleos Escolares del presupuesto, así como otras medidas recientemente adoptadas, son clara manifestación de que los Sres. Consejeros de la Mayoría no piensan 
como nosotros. Es ésta, como se desprende de la importancia del asunto, una discrepancia fundamental.

Resumo, pues, esta parte de mi exposición diciendo que la tercera razón de mi renuncia está dada por esta evidente oposición entre lo que los maestros pensamos que debe ser nuestra escuela campesina y las disposiciones adoptadas por el Consejo de Enseñanza que afectan al desarrollo de la educación rural.

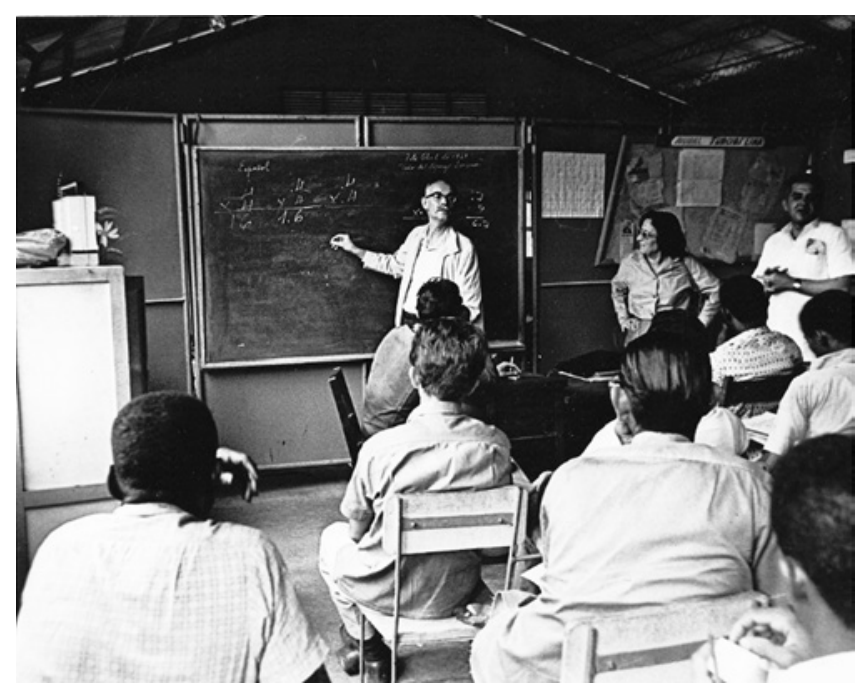

Miguel Soler impartiendo una clase (Archivo de Miguel Soler, años cincuenta)

Estas tres razones que me he permitido analizar extensamente me llevan a pedir al Sr. Director General se acepte esta renuncia y se me exima del dolor de ver desfallecer este trabajo.

Con ello se cierra un episodio más en la lucha del magisterio rural. No hemos alcanzado aún el triunfo, ni aceptamos sentirnos derrotados, porque cada día somos más y sabemos mejor lo que queremos. La jornada ha sido intensa, pero llena de goces, que son nuestros para siempre. Y la fe en nuevas jornadas, luminosas y fecundas, no nos abandonará jamás.

Saludo al Sr. Director General muy atentamente.

Miguel Soler. 


\section{DESDE EL FONDO DEL TIEMPO OTRO TIEMPO}

En 2005 el Frente Amplio ganó las elecciones en Uruguay y muchas cosas empezaron a cambiar en la educación pública, entre ellas el despertar de la memoria de lo realizado como base para la transformación del porvenir. Pocos años después Miguel Soler, que vivía entonces en Barcelona, regresó a Montevideo definitivamente para aportar sus conocimientos en la tarea común. La Escuela 60 de La Mina, donde se encontraba su casa, se ha convertido en un lugar icónico para los educadores en Uruguay. Está previsto hacer un museo y lo que es más importante un lugar de reflexión sobre la educación rural. La experiencia del Núcleo comenzó a aparecer en los libros como ejemplo de buen hacer y los reconocimientos a la labor realizada han permitido soñar de nuevo con que iniciativas de ese tipo son viables y, sobre todo, justas.

El último texto de este artículo es por tanto un documento de esperanza. Se trata de parte de un discurso escrito por Soler con motivo de la inauguración el 20 de abril de 2015 de una escultura en la Escuela 60 con el título Experiencia colectiva.

Me vienen a la memoria centenares de nombres de entidades y personas que dieron su respaldo al trabajo que hace medio siglo realizó durante seis años el Núcleo de La Mina. Me limitaré, puramente a vía de muestra de la riqueza y variedad del apoyo recibido, a mencionar en la escala nacional a Enrique Brayer, en la departamental a Carlos Crespi y a la Voz de Melo y en el plano profesional y personal, a Renée Behar, que conoció La Mina como estudiante de magisterio y que, ya titulada, nos remitió el importe total de su primer sueldo.

Me complace recordar también a Margaret Anstee, Representante de las Naciones Unidas en el Uruguay, que comprendió lo que estábamos haciendo, y fue la portavoz de la dimensión internacional que alcanzó a tener el Núcleo de La Mina.

Saludo con mi gran afecto de siempre a los componentes del equipo de trabajo en La Mina. Vinieron de diversos horizontes: la mayoría del Departamento de Cerro Largo, otros del resto de la República, con y sin experiencia en el medio rural, algunos de ellos estudiantes de magisterio pero miembros experimentados de las Misiones Socio Pedagógicas. 
Para contribuir al carácter integral que quisimos dar al ensayo, Salud Pública mantuvo en La Mina a tres enfermeras universitarias. Fueron ellas las primeras enfermeras rurales con que contó Uruguay. Retengo una admiración sin límites por su trabajo pionero como «enfermeras a caballo».

Y en el sector agrícola, contábamos con un Experto Agrario egresado de UTU y el Ministerio de Ganadería y Agricultura radicó en La Mina sucesivamente a dos Ingenieros Agrónomos, que cumplieron un provechoso trabajo de extensión agrícola.

Con el paso del tiempo, este plantel tuvo oportunidad de difundir e intercambiar sus experiencias a lo largo y lo ancho del país. Una parte del personal gozó de becas de perfeccionamiento en diversas instituciones de América Latina. Fueron dignos portavoces de la educación rural uruguaya y, a su regreso, supieron compartir sus nuevos conocimientos.

Algunos miembros de este colectivo profesional han podido estar aquí presentes. Doy testimonio de su competencia, su entrega incansable a la labor, su creatividad, su espíritu fraterno, su capacidad para garantizar el clima de convivencia solidaria que superó los múltiples obstáculos y la pobreza de medios que tuvimos que enfrentar.

Otro grupo de trabajadores del Núcleo no nos acompaña esta tarde. Su edad no lo ha permitido. Algunos, demasiados, nos fueron dejando definitivamente. Me permitirán que mencione a mi esposa, Nelly Couñago, fallecida en 1965 en México. Fue la Maestra de Educación Estética del Núcleo. Recorría las siete escuelas en su charret llevando a niños, jóvenes y adultos un componente esencial y casi siempre ausente de la vida campesina: la alegría.

Quiero tener una palabra de recuerdo para los niños y vecinos de nuestras escuelas de entonces. De los niños me consta que en algún grado sus vidas integraron definitivamente algunos aspectos de la labor formativa del Núcleo. De los jóvenes me limitaré a mencionar las palabras de uno de ellos: si el Núcleo desapareciera, "sería como si nos cortaran las alas». Respecto a las vecinas y vecinos, creo interpretar el sentir de todos los trabajadores del Núcleo al decirles que, como lo expresa el nombre de la escultura hoy inau- 
gurada, fue para nosotros una extraordinaria experiencia avanzar con la buena voluntad de todos hacia el establecimiento de vínculos, en muchos casos amistosos, que nos llevaron a trabajar en colectividad, de muy variadas maneras, sembrando los gérmenes de una necesaria transformación. A aquellos y aquellas aquí presentes, les doy las gracias por su comprensión, su esfuerzo y, cuando las circunstancias lo exigieron, su defensa de la experiencia.

No he dicho ni diré nada sobre lo que llamamos el «desmantelamiento del Núcleo», ocurrido a principios de 1961. Ya lo hice en oportunidad en que las autoridades departamentales dejaron constancia del infausto hecho al colocar en esta Escuela 60 una placa recordatoria del cincuentenario del mismo.

Prefiero concluir con una referencia de presente y de futuro. Al término de esta ceremonia, el Instituto Nacional de Colonización formalizará la entrega en arrendamiento de nuevas parcelas de tierra, como parte de un conjunto de 773 hectáreas, que han venido recibiendo varios colectivos de trabajadores rurales, con un total de 24 familias. Esto es lo que, a una distancia que se ha hecho demasiado larga, ambicionábamos desde el Núcleo: ir transformando nuestra ruralidad para hacerla justa, eficiente, digna y humana. Yo tengo una larga deuda, que ahora no puedo detallar, con el Instituto Nacional de Colonización. El acto de hoy culmina una relación de casi setenta años y me llena de alegría que tenga lugar, un día de fiesta, en una escuela rural. Como me llena de emoción que esta importante colonia lleve el nombre del Maestro Mártir Julio Castro. ${ }^{9}$ Trabajamos juntos y nos quisimos mucho durante casi cuarenta años.

De modo que felicitaciones a los nuevos colonos y mis mejores deseos de éxito, al Instituto Nacional de Colonización, a las autoridades de la educación inicial y primaria que reafirman la coordinación de su labor con este Instituto. La de hoy es, para el país, una memorable jornada que, apoyándose en un pasado soñador, apunta decididamente a un futuro mejor, como lo quiso Artigas, hace exactamente 200 años, al aprobar su Reglamento

\footnotetext{
${ }^{9}$ El maestro Julio Castro fue detenido y desaparecido por la dictadura militar el 3 de agosto de 1977. Su amigo Miguel no cesó nunca de buscarlo hasta que por fin fue encontrado en 2011. Hoy descansa en paz en el cementerio de Montevideo.
} 
Provisorio para el Fomento de la Campaña. Gracias por ello, Socorro, gracias por ello, Jacqueline.

Termino: cuando en marzo de 1961 di por concluida mi actuación en el Núcleo, la Voz de Melo me cedió su micrófono para que pudiera explicar las razones de mi partida a los niños, maestros y vecinos de La Mina y a la ciudadanía de Cerro Largo. Al concluir mi exposición, dije esta palabra: «Volveremos». Como ven, hemos vuelto, fortalecidos para seguir trabajando por el futuro de la Patria. Porque, como nos dejó dicho Eduardo Galeano, «Otro mundo es posible».

En Cerro Largo, a doce kilómetros de la Colonia Maestro Julio Castro, se encuentra desde hace seis años la Colonia Misiones Sociopedagógicas Maestro Miguel Soler.

\section{BREVE CRONOLOGÍA DE MIGUEL SOLER ROCA}

1922. Nace en Corbera de Llobregat (Barcelona).

1926. La familia Soler Roca emigra a Montevideo. Miguel aprende el español en la Escuela Pública n. ${ }^{\circ} 4$ de Montevideo.

1939. Se gradúa como maestro en los Institutos Normales de la capital.

1940-1942. Como la legislación uruguaya no permite a los extranjeros ejercer

el magisterio, Soler trabaja en una industria frigorífica hasta que consigue nacionalizarse.

1943. Primer trabajo como maestro rural en el rancherío de Los Vázquez (Tacuarembó).

1945-1947. Maestro en Montevideo y Secretario de la Federación Uruguaya del Magisterio (FUM)

1946. Participa en la Misión Sociopedagógica de Arroyo del Oro, Departamento de Treinta y Tres.

1947. Se casa con la maestra Nelly Couñago.

1948-1954. Maestro en la Escuela Rural n. ${ }^{\circ} 59$ en el Departamento de Soriano. La UNESCO le concede una beca para estudiar en el CREFAL (México), como Especialista en Educación Fundamental.

1949. Es uno de los redactores del Programa para las Escuelas Rurales.

1954-1961. Proyecto de creación del Primer Núcleo Experimental de La Mina.

Director del mismo hasta 1961. 
1961. Sale del país como especialista de la UNESCO. Se le encarga asesorar al Ministerio de Educación boliviano en el diseño de un Plan de Desarrollo Rural.

1964-1969. Director del CREFAL.

1965. Fallece Nelly Couñago de Soler.

1966. Se casa con la maestra y trabajadora social Matilde Espino.

1969-1974. Especialista en educación de adultos en la Oficina Regional de Educación para América Latina y el Caribe (OREALC/UNESCO) en Santiago de Chile. Desde ese puesto asiste al Golpe de Estado de Pinochet.

1974-1977. Director de la División de Alfabetización, Educación de Adultos y Desarrollo Rural de la UNESCO en París.

1977-1982. Subdirector General Adjunto del Sector Educación de la UNESCO. 1982. Se jubila de la UNESCO y fija su residencia en Barcelona. Continúa trabajando como consultor.

1984. Miembro del Grupo de Educación de la Comisión Española de la UNESCO.

1985-1991. Asesor de la Secretaría de Educación de la Provincia de Córdoba en Argentina y del Gobierno Sandinista en Nicaragua.

1999-2002. Miembro del Grupo de Educación de la Comisión Catalana de Relaciones con la UNESCO.

2005. Regresa a Montevideo. Asesor honorario del Consejo Directivo Central (CODICEN) de la Administración Nacional de Educación Pública (ANEP) en el debate educativo previo a la Ley de Educación uruguaya.

2007. Vuelve a residir en Barcelona hasta que en 2010 se instala definitivamente en Montevideo.

2010. Funda el Grupo de Reflexión sobre Educación (GRE).

2012-actualidad. Además del GRE, integra el Movimiento de Educadores por la Paz, realiza actividades de extensión con la Universidad de la República y participa en iniciativas de los Institutos Normales de Montevideo.

\section{Nota sobre la autora}

MARía García Alonso es profesora del departamento de Antropología Social y Cultural de la UNED, doctora por el mismo departamento y licenciada en Geografía e Historia (especialidad Antropología de América) por la Universidad Complutense de Madrid. Es miembro de la Junta directiva del Centro Internacional de Memoria y Derechos Humanos (CIEMEDH) de la UNED. Ha sido Vicerrectora de Formación Permanente y Subdirectora del Centro de Estudios de Migraciones y Exilios de la misma univer- 
sidad y presidenta de la Red Internacional de Estudios de Territorio y Cultura (RETEC).

Estudia las relaciones entre la antropología y la historia, especialmente a través de la reconstrucción de la memoria colectiva de los actores sociales ya sea a través del trabajo de campo o de recursos archivísticos. Ha realizado trabajo de campo en España sobre las Misiones Pedagógicas (19311936) y sobre el proceso de exhumaciones de la guerra civil y su impacto social; en Colombia sobre distintas repercusiones sociales del conflicto armado; y en Uruguay, sobre la recuperación de la memoria de las instituciones educativas tras la dictadura.

Sus preocupaciones teóricas se complementan con su interés por formas alternativas de presentación de los resultados de las investigaciones de modo que permitan tanto la participación de los protagonistas sobre los procesos vividos, como el debate académico. Ha sido comisaria entre otras de las exposiciones Las Misiones Pedagógicas (1931-1936) en el Cuartel del Conde Duque (Madrid) y otras ciudades (2006-2007) y Las Misiones Sociopedagógicas entre España y América: México-España-Uruguay (Montevideo, 2009).

\section{Referencias}

ComAndo GenERAL DEl EjÉrcito. Testimonio de una nación agredida. Montevideo: División de Publicaciones y Ediciones Universidad de la República, 1978. Soler RocA, Miguel. Réplica de un maestro agredido. Educar en Uruguay: de la construcción al derribo, de la resistencia a la esperanza. Montevideo: Ediciones Trilce, 2005. 